\title{
O USO DE INTELIGÊNCIA ARTIFICIAL NA TOMADA DE DECISÕES JUDICIAIS: UMA ANÁLISE SOB A PERSPECTIVA DA CRÍTICA HERMENÊUTICA DO DIREITO
}

\section{ARTIFICIAL INTELLIGENCE IN JUDICIAL DECISION-MAKING: AN ANALYSIS FROM THE PERSPECTIVE OF THE HERMENEUTIC CRITICISM OF LAW}

\author{
Bianca Kaini Lazzaretti ${ }^{1}$ \\ ORCID: https://orcid.org/0000-0002-3824-6028 \\ Raquel von Hohendorff ${ }^{2}$ \\ ORCID: https://orcid.org/0000-0001-7543-2412
}

Submissão: 11/02/2021 / Aceito: 12/03/2021 / Publicado: 19/04/2021

\begin{abstract}
Resumo
Em um contexto de rápida e constante evolução tecnológica, característica da Quarta Revolução Industrial, já se fala na utilização de inteligência artificial no âmbito jurídico - inclusive para fins de prestação jurisdicional. Entretanto, é preciso discutir as bases teóricas que suportam essa possibilidade, de modo a avaliar o atendimento ao que se espera como decisão judicial adequada em um Estado Democrático de Direito. Nesse sentido, o presente artigo possui, como problema de pesquisa, a seguinte questão: em que medida, sob o ponto de vista da Crítica Hermenêutica do Direito, é possível a utilização de ferramentas da tecnologia da informação, especialmente de inteligência artificial, na tomada de decisões judiciais? Por meio do "método" fenomenológico-hermenêutico, buscou-se: apresentar os aspectos práticos relevantes acerca do uso de algoritmos na atividade do magistrado; compreender a teoria que sustenta essa prática - o realismo jurídico; bem como ilustrar a perspectiva da Crítica Hermenêutica do Direito acerca da adoção da tecnologia como auxiliar ou substituta do juiz. Concluiu-se que a tomada de decisão judicial por máquinas computacionais é incompatível com a Crítica Hermenêutica do Direito, podendo-se falar tão somente no auxílio

\footnotetext{
${ }^{1}$ Mestranda em Direito Público pela Universidade do Vale do Rio dos Sinos (UNISINOS). Bolsista CAPES/PROEX. Pós-graduanda em Direito da Seguridade Social pela Faculdade Legale. Graduada em Direito pela UNISINOS (bolsista PROUNI), com período de estudos na Universidade do Porto (bolsista Santander). Integrante da Clínica de Direitos Humanos da Universidade Federal do Paraná (CDH | UFPR). Advogada. E-mail: biancalazzaretti@live.com.

${ }^{2}$ Doutora em Direito Público Unisinos (bolsista CAPES). Mestre em Direito Público pela Unisinos (Conceito CAPES 6, bolsista CAPES). Professora do Programa de Pós-Graduação em Direito - Mestrado e Doutorado da UNISINOS, ministrando a disciplina Educação, Transdisciplinaridade e Transformação Social. Participante do grupo de pesquisa JUSNANO (CNPq/Unisinos). E-mail: vetraq@gmail.com.
} 
tecnológico para a separação e classificação de documentos processuais, mas não em minutas de decisão ou sugestões de sentenças.

Palavras-chave: Inteligência artificial. Decisão judicial. Crítica Hermenêutica do Direito.

\begin{abstract}
In a context of constant, fast technological evolution, typical of the Fourth Industrial Revolution, the usage of artificial intelligence in the legal field is already being looked upon - even considering the making of court decision. However, the theoretical basis that support this possibility need discussion in order to evaluate the fitness to what is expected as a decision in a Democratic State of Rights. In that sense, this article has as its research problem the following question: to what extent, under the Hermeneutic Criticism of Law point of view, it is possible to use information technology tools, notably artificial intelligence, at legal decision making? Through the hermeneutical phenomenology "method", we sought to: present the relevant practical aspects about the use of algorithms in the judge activity; understand the theory that support this usage - the legal realism; as well as to illustrate the Hermeneutic Criticism of Law perspective about the adoption of technology as assistant or substitute to a judge. We conclude that the decision making through computational machines is incompatible with the Hermeneutic Criticism of Law, making it possible to conceive only the technological aid to the categorization and selection of court documents but not to ruling drafts or sentence suggestions.
\end{abstract} Keywords: Artificial intelligence. Judicial decision-making. Legal realism. Hermeneutic Criticism of Law.

\title{
INTRODUÇÃO
}

Desde os anos de 1960, vive-se um movimento de expansão tecnológica cada vez mais intenso. Chegamos à segunda década do século XXI com uma constatação: "estamos no início de uma revolução que alterará profundamente a maneira como vivemos, trabalhamos e nos relacionamos", a Quarta Revolução Industrial. ${ }^{3}$ Depois da Primeira, Segunda e Terceira Revoluções Industriais (Agrícola, Industrial e Digital, respectivamente), a Quarta grande revolução é marcada por "uma internet mais ubíqua e móvel, por sensores menores e mais poderosos que se tornam mais baratos e pela inteligência artificial e aprendizagem automática (ou aprendizado de máquina)", ou seja, pela "Indústria 4.0". ${ }^{4}$

É nesse contexto que, cada vez mais, se fala na utilização de novas tecnologias para a realização do trabalho - inclusive jurídico. Diversos estudos têm se preocupado em estimar a probabilidade de que determinadas profissões sejam plenamente computadorizadas, com a

SCHWAB, Klaus. A Quarta Revolução Industrial. São Paulo: EDIPRO, 2019. E-book (sem paginação).

${ }^{4}$ SCHWAB, Klaus. A Quarta Revolução Industrial. São Paulo: EDIPRO, 2019. E-book (sem paginação). 
substituição da mão de obra humana. ${ }^{5}$ De acordo com Frey e Osborne, atividades jurídicas como a advocacia e a magistratura possuem risco médio de automação (embora os autores não entendam que seja possível seu exercício sem a participação humana), enquanto para assistentes e secretárias nessa área a chance é alta (e real). ${ }^{6}$

A proposta, nesse sentido, não é a de substituição do profissional, porquanto a tecnologia é colocada como aliada do jurista. São diversas iniciativas que propõem auxiliar o advogado na busca de jurisprudência, na análise dos riscos e teses viáveis em um processo, ou mesmo na redação de petições. ${ }^{7}$ Entretanto, não é apenas a defesa que pode contar com ferramentas high tech: no âmbito dos tribunais, já se fala em automatização de tarefas tidas como burocráticas, assim como de auxílio, por meio de inteligência artificial, na tomada de decisão. Inclusive no Brasil.

Dessa forma, esse artigo tem como problemática de pesquisa a seguinte questão: em que medida, sob o ponto de vista da Crítica Hermenêutica do Direito, é possível a utilização de ferramentas da tecnologia da informação, especialmente de inteligência artificial, na tomada de decisões judiciais?

A justificativa para a escolha deste tema está no fato de que a ligação entre Direito e tecnologia é cada dia mais forte. Nesse contexto, muito se questiona acerca dos impactos práticos do uso da

\footnotetext{
5 Nesse ponto, muito se tem citado as obras de Richard e Daniel Susskind, que afirmam que "[...] o mundo jurídico vai mudar mais radicalmente nas próximas duas décadas do que mudou nos últimos dois séculos". SUSSKIND, Richard; SUSSKIND, Daniel. The future of the professions: how technology will transform the work of human experts. Oxford: Oxford University Press, 2015. p. 66. SUSSKIND, Richard. Tomorrow's lawyers: an introduction to your future. 2. ed. Oxford: Oxford University Press, 2017.
}

6 FREY, Carl Benedikt; OSBORNE, Michael A. The future of employment: how susceptible are jobs to computerisation? Oxford: University of Oxford, 2013. Disponível em: https://linkinghub.elsevier. com/retrieve/pii/S0040162516302244. Acesso em: 30 jan. 2021.

7 Foge do objetivo deste trabalho explorar todas as tecnologias de assistência à advocacia. Porém, alguns exemplos merecem ser citados. A plataforma ROSS, que fazia uso do sistema Watson, da IBM, obteve grande popularidade no ano de 2017, quando foi adotado pelo escritório norte-americano Baker \& Hostetler. O robô, como foi chamado, prometia ser um "programa de pesquisa jurídica feito para buscas rápidas e em profundidade", analisando petições e documentos para fazer sugestões ao advogado. Em janeiro de 2021, o sistema foi descontinuado por conta do litígio com a Westlaw, da Thomson Reuters, que tem uma proposta similar. Outra plataforma com finalidades semelhantes é a e-Discovery, que analisa documentos e exporta dados em formato de gráficos, prometendo agilidade, redução do esforço manual e propensão a erros humanos. ROSS, o primeiro robô advogado do mundo. In: TRANSFORMAÇÃO Digital. São Paulo, 6 jun. 2018. Disponível em: https://transformacaodigital.com/juridico/ross-o-primeiro-roboadvogado-do-mundo. Acesso em: 2 fev. 2021. ROSS INTELLIGENCE. Features. San Francisco: ROSS, [2020?]. Disponível em: https://rossintelligence. com/features.html. Acesso em: 2 fev. 2021. AMBROGI, Robert. ROSS comes out swinging, vows to fight Thomson Reuters' lawsuit alleging data theft. In: AMBROGI, Robert. LawSites. [S. l.], May 7 2020. Disponível em: https://www.lawsitesblog.com/2020/05/ross-comes-out-swinging-vows-to-fightthomson-reuters-lawsuit-alleging-data-theft.html. Acesso em: 2 fev. 2021. VERITAS. Plataforma eDiscovery: investigação digital, investigações e revisão de documentos. Santa Clara: Veritas, [2021?]. Disponível em: https://www.veritas. com/pt/br/insights/ediscovery-platform. Acesso em: 2 fev. 2021. 
inteligência artificial nos julgamentos, ignorando a necessidade de apreciação das bases teóricas que permitam (ou não) a adoção dessas ferramentas - como se fosse possível dissociar completamente teoria e prática. Daí a relevância de uma análise do problema sob uma perspectiva hermenêutica.

Para responder à pergunta proposta, o presente artigo é composto em duas partes, trabalhadas a partir do "método" fenomenológico-hermenêutico. ${ }^{8}$ A primeira trará uma compreensão geral acerca do uso de inteligência artificial na tomada de decisões judiciais, indicando alguns exemplos de algoritmos já em desenvolvimento ou em uso no país. A segunda busca averiguar a teoria que possibilita o uso dessa tecnologia, para essa finalidade, no Direito, investigando suas limitações no Estado Democrático de Direito, sob a perspectiva da hermenêutica jurídica.

Essa análise é pautada pela perspectiva da Crítica Hermenêutica do Direito, conforme traçada por Lenio Luiz Streck com base nos estudos de Heidegger, Gadamer e Dworkin, ${ }^{9}$ caracterizada “ [...] pela exploração do elemento hermenêutico que se apresenta no cerne do fenômeno jurídico colocando enfoque, como objeto privilegiado de análise, nos problemas relativos à decisão jurídica". ${ }^{10}$ Além disso, buscou-se literatura, nacional e estrangeira, de outras áreas do conhecimento que pudessem auxiliar na compreensão do funcionamento e dos impactos das novas tecnologias no Direito.

\section{ESTABELECENDO AS BASES PARA A COMPREENSÃo DO USO DE INTELIGÊNCIA ARTIFICIAL NA TOMADA DE DECISÕES JUDICIAIS}

O que é isto - inteligência artificial? A resposta está longe de ser simples e breve. ${ }^{11}$ Para Russell e Norvig, trata-se de um campo de estudo que busca "não apenas compreender, mas também construir entidades inteligentes". ${ }^{12}$ Os autores identificam uma variedade de definições possíveis, nas quais a inteligência artificial pode estar relacionada ao comportamento ou ao raciocínio, mimetizando a ação ou razão humana, ou, ainda, medindo seu sucesso a partir de um ideal de racionalidade (nem

\footnotetext{
8 A palavra método colocada entre aspas justifica-se pelo fato de a hermenêutica, segundo Streck, ser antimetodológica. STRECK, Lenio Luiz. Lições de Crítica Hermenêutica do Direito. Porto Alegre: Livraria do Advogado, 2014.

9 STRECK, Lenio Luiz. O que é isto: decido conforme minha consciência? Porto Alegre: Livraria do Advogado, 2013.

${ }^{10}$ STRECK, Lenio Luiz. Verdade e consenso. 6 ed. rev. e ampl. São Paulo: Saraiva, 2017. E-book. p. 33.

${ }^{11}$ Motivo pelo qual, aqui, não se pretende exaurir o assunto. Nesse sentido, a finalidade é tão somente expor alguns conceitos basilares para a compreensão do que se tem como inteligência artificial (e seus desdobramentos) e dos motivos pelos quais se tem apostado nessa(s) ferramenta(s) como possibilidade para o âmbito jurídico.

${ }^{12}$ RUSSELL, Stuart; NORVIG, Peter. Inteligência artificial. Rio de Janeiro: Elsevier, 2013. E-book (não paginado).
} 
sempre alcançado pelo ser humano). Cada uma dessas categorias vem se desenvolvendo ao longo dos anos, a depender da área de estudo e da sua finalidade, de forma independente, porém conectada. ${ }^{13}$

Sob um ponto de vista mais geral e resumido, é possível compreender a inteligência artificial "[...] como o desenvolvimento de ferramentas informáticas que emulem a inteligência humana ou que executem funções a ela relacionadas, tais como raciocínio, aprendizagem, adaptabilidade, percepção e interação com o meio físico etc.". ${ }^{14}$ Pode-se obter inteligência artificial por meio de diversas técnicas, dentre as quais o machine learning, ou aprendizado de máquina, que possui várias abordagens possíveis, como é o caso do aprendizado profundo, relacionado às redes neurais artificiais. $^{15}$

É por meio dessas tecnologias, pautadas no processamento computacional de dados cada vez mais ágil e qualificado, que se fala em utilização de inteligência artificial na tomada de decisões judiciais. Aqueles que defendem esse uso, costumam classificar as possibilidades conforme a atividade desempenhada pelos algoritmos. Para Sourdin:

[...] há três formas principais pelas quais a tecnologia já está remodelando o sistema de justiça. Primeiro, e no nível mais básico, a tecnologia está ajudando a informar, apoiar e aconselhar as pessoas envolvidas no sistema de justiça (tecnologia de apoio). Segundo, a tecnologia pode substituir funções e atividades que antes eram realizadas por humanos (tecnologias de substituição). Finalmente, em um terceiro nível, a tecnologia pode mudar o

${ }^{13}$ RUSSELL, Stuart; NORVIG, Peter. Inteligência artificial. Rio de Janeiro: Elsevier, 2013. E-book (não paginado).

${ }^{14}$ MEDINA, José Miguel Garcia; MARTINS, João Paulo Nery dos Passos. A era da inteligência artificial: as máquinas poderão tomar decisões judiciais? Revista dos Tribunais, [s. l.], v. 1020/2020, p. 2, out. 2020. Disponível em: https://cutt.ly/0knyKSP. Acesso em: 15 jan. 2020.

${ }^{15}$ Machine learning é a habilidade de um sistema aprender a partir de dados previamente fornecidos, realizando associações e transformando suas conclusões em previsões corretas, exprimidas como novos dados - tendo os dados iniciais sido classificados por seres humanos ou não. Isso é possibilitado por meio do processamento de linguagem natural (natural language processing), que é a capacidade do programa compreender a linguagem humana e transformála em linguagem de programação. O aprendizado profundo (deep learning) caracteriza-se como um processo em que "o próprio algoritmo detecta seus erros e realiza os ajustes necessários para aprimorar seus resultados", sendo "algoritmo" um conjunto de passos que um programa computacional executa para resolver um problema. Artificial neural networks são "unidades computacionais [...] conectadas entre si e divididas em camadas", imitando, rudimentarmente, as redes neurais biológicas. Atualmente, as redes neurais artificiais já possuem diversas camadas intermediárias, cada uma responsável por uma tarefa específica, possibilitando que a inteligência artificial se ocupe de problemas cada vez mais complexos. BOEING, Daniel Henrique Arruda. Ensinando um robô a julgar: pragmática, discricionariedade e vieses no uso de aprendizado de máquina no Judiciário. Trabalho de Conclusão de Curso (Graduação em Direito) - Universidade Federal de Santa Catarina, Florianópolis, 2019. Disponível em: https://repositorio.ufsc.br/bitstream/handle/123456789/

203514/TCC\%20$\% 20$ Ensinando\%20um\%20rob\%c3\%b4\%20a\%20julgar\%201-3-merged.pdf?sequence=1\&i sAllowed=y. Acesso em: 15 jan. 2021. p. 20-21. TACCA, Adriano; ROCHA, Leonel Severo. Inteligência artificial: reflexos no sistema do direito. Revista do Programa de Pós-Graduação em Direito da UFC, Fortaleza, v. 38, n. 2, p. 53-68, jul./dez. 2018. Disponível em: www.periodicos.ufc.br/nomos/article/ download/20493/95963. Acesso em: 15 jan. 2021. 
modo como os juízes trabalham e fornecer formas de justiça muito diferentes (tecnologia disruptiva) [...]. ${ }^{16} 17$

Medina e Martins também classificam em três níveis a possibilidade de utilização da inteligência artificial no âmbito judicial. No primeiro, ela é usada como uma “[...] ferramenta auxiliar, assistindo a atividade decisória desempenhada pelo ser humano, que permanece com a responsabilidade pela decisão tomada", ${ }^{18}$ como é o caso da triagem de processos por assunto e das ferramentas de pesquisa jurisprudencial, legislativa e doutrinária. No segundo, a inteligência artificial seria responsável por realizar atos ordinatórios e "[...] mesmo despachos mais singelos [...]", ${ }^{19}$ deixando que o juiz profira somente decisões como as interlocutórias e as sentenças. Por fim, no terceiro nível, as decisões judiciais seriam totalmente automatizadas, substituindo os juízes. ${ }^{20}$

Para Boeing, os três tipos de uso do aprendizado de máquina no Direito são: a) classificador; b) relator; c) robô-juiz. O primeiro tipo tem como função a busca de materiais que possam fundamentar decisões. A segunda forma, para além da mera pesquisa de documentos, deve ser capaz de analisar o material encontrado, aprofundando-se em sua estrutura e até mesmo realizando previsões de decisões tomadas por certos tribunais. O terceiro tipo também poderia realizar previsões, mas, por seu alto grau de precisão ou pela baixa complexidade do caso, elas seriam tomadas como decisões por si mesmas - dispensando a atuação do juiz. ${ }^{21}$

${ }^{16}$ Tradução livre de: "[...] there are three main ways in which technology is already reshaping the justice system. First, and at the most basic level, technology is assisting to inform, support and advise people involved in the justice system (supportive technology). Second, technology can replace functions and activities that were previously carried out by humans (replacement technologies). Finally, at a third level, technology can change the way that judges work and provide for very different forms of justice (disruptive technology) [...]".

${ }^{17}$ SOURDIN, Tania. Judge v Robot? Artificial intelligence and judicial decision-making. University of New South Wales Law Journal, Sydney, v. 41, n. 4, p. 1117, 2018. Disponível em: http://www8.austlii.edu.au/cgibin/viewdoc/au/journals/UNSWLawJ1/2018/38.html. Acesso em: 3 fev. 2021.

${ }^{18}$ MEDINA, José Miguel Garcia; MARTINS, João Paulo Nery dos Passos. A era da inteligência artificial: as máquinas poderão tomar decisões judiciais? Revista dos Tribunais, [s. l.], v. 1020/2020, p. 9, out. 2020. Disponível em: https://cutt.ly/0knyKSP. Acesso em: 15 jan. 2020.

${ }^{19}$ MEDINA, José Miguel Garcia; MARTINS, João Paulo Nery dos Passos. A era da inteligência artificial: as máquinas poderão tomar decisões judiciais? Revista dos Tribunais, [s. l.], v. 1020/2020, p. 10, out. 2020. Disponível em: https://cutt.ly/0knyKSP. Acesso em: 15 jan. 2020.

${ }^{20}$ MEDINA, José Miguel Garcia; MARTINS, João Paulo Nery dos Passos. A era da inteligência artificial: as máquinas poderão tomar decisões judiciais? Revista dos Tribunais, [s. l.], v. 1020/2020, p. 9-10, out. 2020. Disponível em: https://cutt.ly/0knyKSP. Acesso em: 15 jan. 2020.

${ }^{21}$ BOEING, Daniel Henrique Arruda. Ensinando um robô a julgar: pragmática, discricionariedade e vieses no uso de aprendizado de máquina no Judiciário. Trabalho de Conclusão de Curso (Graduação em Direito) - Universidade Federal de Santa Catarina, Florianópolis, 2019. Disponível em: https://repositorio.ufsc.br/ bitstream/handle/123456789/203514/TCC\%20-\%20Ensinando\%20um\%20rob\%c3\%b4\%20a\%20julgar\%201-3merged.pdf?sequence=1\&isAllowed=y. Acesso em: 15 jan. 2021. 
Esse terceiro nível, ou tipo, citado pela doutrina (ainda) não existe na prática - uma completa substituição do magistrado na tarefa decisória - eis que ainda é necessária, no mínimo, uma revisão da decisão produzida pelo algoritmo. O que se tem atualmente são ferramentas que possibilitam a triagem, classificação e organização de documentos e peças processuais, que realizam pesquisa de legislação, jurisprudência (inclusive com finalidade preditiva) e literatura jurídica, bem como começam a ser introduzidos algoritmos capazes de sugerir esboços de decisões judiciais.

São diversos os exemplos de algoritmos atuantes nos tribunais brasileiros. O que mais tem atraído atenção, desde seu lançamento, em 2018, é o VICTOR, projeto encomendado pelo Supremo Tribunal Federal (STF) à Universidade de Brasília. Sob a promessa de agilizar a tramitação de processos, o programa é tido como o "[...] maior e mais complexo Projeto de [inteligência artificial] do Poder Judiciário e, talvez, de toda a Administração Pública Brasileira". 22 Sua promessa é realizar a leitura dos recursos extraordinários recebidos pelo Tribunal, identificando quais se vinculam a temas de repercussão geral, tendo apresentado $93 \%$ de assertividade em testes. ${ }^{23} \mathrm{~A}$ ideia é que ele não fique adstrito a esse objetivo inicial e, por isso, a ampliação de suas habilidades já era discutida desde antes de seu lançamento - condicionada, de certa maneira, às limitações da própria tecnologia. ${ }^{24}$

Mas há outros sistemas que já são usados nos tribunais brasileiros. ${ }^{25} \mathrm{O}$ sistema $\mathrm{SAJ}$ Tribunais, utilizado pelos Tribunais de Justiça dos Estados do Acre, Alagoas, Amazonas, Ceará, Mato Grosso do Sul, Santa Catarina e São Paulo, conta com seis categorias de documentos: despacho, decisão interlocutória, sentença, termo de audiência, ato ordinatório e ajuizamento. Todos esses atos podem:

[...] ser emitidos de forma totalmente automática ou podem ser configurados para serem apenas preparados para conferência e continuação em cartório em momento posterior. Assim,

\footnotetext{
${ }^{22}$ INTELIGÊNCIA artificial vai agilizar a tramitação de processos no STF. In: SUPREMO TRIBUNAL FEDERAL (STF).Notícias STF.Brasília, $\quad$ DF, $30 \quad$ maio $2018 . \quad$ Disponível em: http://www.stf.jus.br/portal/cms/verNoticiaDetalhe.asp?idConteudo=380038. Acesso em: 9 jan. 2021.

${ }^{23}$ SOUSA, Weslei Gomes De. Inteligência artificial e celeridade processual no Judiciário: mito, realidade ou necessidade? Dissertação (Mestrado em Administração) - Universidade de Brasília, Brasília, DF, 2020. Disponível em: https://repositorio.unb.br/bitstream/10482/38772/1/2020_WesleiGomesdeSousa.pdf. Acesso em: 4 fev. 2021.

${ }^{24}$ INTELIGÊNCIA artificial vai agilizar a tramitação de processos no STF. In: SUPREMO TRIBUNAL FEDERAL (STF). Notícias STF. Brasília, DF, 30 maio 2018. Disponível em: http://www.stf.jus.br/portal/cms/verNoticiaDetalhe.asp?idConteudo=380038. Acesso em: 9 jan. 2021.

${ }^{25}$ Várias iniciativas do uso de inteligência artificial pelo país, para além do exemplo aqui citado, foram detalhadas por Engelmann e Fröhlich. Para mais detalhes: ENGELMANN, Wilson; FRÖHLICH, Afonso Vinício Kirschner. Inteligência artificial aplicada à decisão judicial: o papel dos algoritmos no processo de tomada de decisão. Revista Jurídica, Blumenau, v. 24, n. 54, e8274, mai./ago. 2020. Disponível em: https://proxy.furb.br/ojs/index.php/juridica/issue/view/474. Acesso em: 9 jan. 2021.
} 
as determinações do magistrado poderão - ou não - gerar automaticamente os expedientes subordinados a elas sem que seja necessária a atuação do cartório. ${ }^{26}$

O Conselho Nacional de Justiça $(\mathrm{CNJ})$ regulamentou uso de inteligência artificial nos tribunais no final de 2020, por meio da Resolução $\mathrm{n}^{\mathbf{0}}$ 332. A normativa estabelece padrões para a implementação dessa tecnologia, fazendo com que sejam observados os direitos fundamentais dos cidadãos, bem como as regras de governança e proteção de dados, dispondo sobre a necessária diversidade nos grupos responsáveis pela criação e manutenção dos algoritmos. ${ }^{27}$ Porém, esse documento oferece soluções a apenas algumas das implicações práticas do uso dessa tecnologia nos tribunais, ${ }^{28}$ sem considerar, além disso, a importância de uma base teórica.

\section{REVIRANDO O SOLO TEÓRICO: CONSIDERAÇÕES SOBRE O REALISMO JURÍDICO NA TOMADA DE DECISÕES POR ALGORITMOS SOB A PERSPECTIVA DA CRÍTICA HERMENÊUTICA DO DIREITO}

Pode-se pensar que a discussão acerca dos fundamentos teóricos que condicionam a ligação entre Direito e tecnologia está superada diante da constatação de que as máquinas já auxiliam o jurista em suas tarefas. Mas, quando se trata do exercício da jurisdição, é primordial que se identifiquem as teorias que possibilitam a tomada de decisão apoiada por máquinas, de modo a verificar o atendimento aos ideais do Estado Democrático de Direito e os limites necessários ao uso dos algoritmos no Judiciário.

A defesa do uso de inteligência artificial na atividade de julgar parece estar alinhada ao realismo jurídico, seja por uma escolha consciente ou inconsciente dos pesquisadores do assunto. É

\footnotetext{
${ }^{26}$ NASCIMENTO, Heloisa Kreutz do. O que são Atos no SAJ Tribunais? In: QUÍRON. [S. l.], 22 jan. 2021. Disponível em: $\quad$ https://quiron.softplan.com.br/hc/pt-br/articles/360016031993-O-que-s\%C3\%A3o-Atos-no-SAJ-Tribunais-. Acesso em: 3 fev. 2021.

${ }^{27}$ CONSELHO NACIONAL DE JUSTIÇA (CNJ). Resolução no 332, de 21 de agosto de 2020. Brasília, DF: CNJ, 2020. Disponível em: https://www.anoreg.org.br/site/wp-content/uploads/2020/08/Resoluc\%CC\% A7a\%CC\%83o-332CNJ.pdf. Acesso em: 26 ago. 2020.

${ }^{28}$ Como exemplos de desdobramentos na prática não abordados pelo CNJ, tem-se os impactos da automatização no direito à ampla defesa e ao contraditório, questões ligadas aos direitos do autor dos códigos (quando programados por empresas privadas) e ao acesso à justiça. Nesse sentido, surgem questionamentos, como: é possível recorrer das decisões tomadas pelos algoritmos? O advogado terá o conhecimento sobre computação, necessário para compreender todo o processo de coleta e tratamento de dados? Quando feito fora da esfera pública, o programa poderá ser analisado a fundo para que se possa recorrer devidamente das decisões automatizadas?
} 
o que se vê nos trabalhos de Cestari ${ }^{29}$ e Boeing, ${ }^{30}$ por exemplo, e que também é notado por Medina e Martins ${ }^{31}$ e apontado por Streck. ${ }^{32}$ Por isso, é relevante tecer algumas considerações sobre o que é essa teoria e o que ela tem a dizer sobre as decisões judiciais.

Em meados do século XIX, despontou uma corrente de pensamento chamada de pragmatismo. Resumidamente, os pragmatistas buscavam “[...] uma filosofia sem fundamentos ontológicos a priori, sendo a realidade identificada com o conjunto da experiência subjetiva". ${ }^{33} \mathrm{O}$ valor de verdade de uma ideia, para eles, estaria ligado ao seu grau de utilidade e aos efeitos que pudessem ser relevantes na prática. Tal teoria influenciou o realismo jurídico, ${ }^{34}$ também chamado de empirismo jurídico, que “[...] buscava substituir os critérios racionalistas de análise por procedimentos empíricos e/ou utilitaristas". 35

Os realistas propõem que se abandonem certos parâmetros imutáveis do que se entende por justiça, em prol da adoção de um proceder mais experimental e instrumental do Direito, voltado para o futuro e ajustável às necessidades sociais. ${ }^{36}$ Assim, como bem aponta Santos, para os pragmatistas:

[...] muito mais que um sistema balizado na razão, ou um conjunto de regras extraídas por meio do método lógico dedutivo, a partir de princípios éticos ou de axiomas socialmente

${ }^{29}$ CESTARI, Roberto Tagliari. Decisão judicial e realismo jurídico: evolução das pesquisas sobre o comportamento judicial. Dissertação (Mestrado em Direito) - Universidade de São Paulo, Ribeirão Preto, 2016. Disponível em: https://doi.org/10.11606/D.107.2017.tde-01092017-094644. Acesso em: 15 jan. 2021.

${ }^{30}$ BOEING, Daniel Henrique Arruda. Ensinando um robô a julgar: pragmática, discricionariedade e vieses no uso de aprendizado de máquina no Judiciário. Trabalho de Conclusão de Curso (Graduação em Direito) - Universidade Federal de Santa Catarina, Florianópolis, 2019. Disponível em: https://repositorio.ufsc.br/ bitstream/handle/123456789/203514/TCC\%20-\%20Ensinando\%20um\%20rob\%c3\%b4\%20a\%20julgar\%201-3merged.pdf?sequence=1\&isAllowed=y. Acesso em: 15 jan. 2021.

${ }^{31}$ MEDINA, José Miguel Garcia; MARTINS, João Paulo Nery dos Passos. A era da inteligência artificial: as máquinas poderão tomar decisões judiciais? Revista dos Tribunais, [s. l.], v. 1020/2020, out. 2020. Disponível em: https://cutt.ly/0knyKSP. Acesso em: 15 jan. 2020.

${ }^{32}$ STRECK, Lenio Luiz. Um robô pode julgar? Quem programa o robô? Consultor Jurídico, São Paulo, 2020. Disponível em: https://www.conjur.com.br/2020-set-03/senso-incomum-robo-julgar-quem-programa-robo. Acesso em: 9 jan. 2021.

${ }^{33}$ STRECK, Lenio Luiz. Dicionário de Hermenêutica: 50 verbetes fundamentais da Teoria do Direito à luz da Crítica Hermenêutica do Direito. 2. ed. Belo Horizonte: Letramento; Casa do Direito, 2020. p. 343.

${ }^{34}$ Não se ignora a existência de diversas correntes de realismo jurídico, iniciadas nas duas principais tradições do movimento: a norte-americana e a escandinava. Entretanto, fugiria do escopo deste texto elaborar extensas considerações sobre todas as teorias pragmatistas no direito, preferindo-se, portanto, traçar apenas algumas linhas gerais - relevantes para a compreensão da relação entre o empirismo e o uso de inteligência artificial na tomada de decisões judiciais.

${ }^{35}$ STRECK, Lenio Luiz. Dicionário de Hermenêutica: 50 verbetes fundamentais da Teoria do Direito à luz da Crítica Hermenêutica do Direito. 2. ed. Belo Horizonte: Letramento; Casa do Direito, 2020. p. 344

${ }^{36}$ STRECK, Lenio Luiz. Dicionário de Hermenêutica: 50 verbetes fundamentais da Teoria do Direito à luz da Crítica Hermenêutica do Direito. 2. ed. Belo Horizonte: Letramento; Casa do Direito, 2020. 
admitidos, o direito seria exatamente o conteúdo das decisões judiciais ou a própria avaliação que os tribunais fariam dos fenômenos sociais. ${ }^{37}$

Eis o protagonismo do magistrado no realismo jurídico. O foco está na ideia de que o juiz possa decidir com base no que entende mais "efetivo" - conceito aberto de difícil definição na sociedade democrática complexa. ${ }^{38}$ Nesse sentido, os empiristas acreditam que os juízes não decidem apenas com base em elementos jurídicos, ${ }^{39}$ sendo influenciados por vieses ${ }^{40}$ e heurísticas, ${ }^{41}$ e buscando fundamentos em outras áreas do saber, como na psicologia e na economia, por exemplo. ${ }^{42}$

Apesar de ter sido criticado por autores positivistas, como H. L. A. Hart, ${ }^{43}$ o realismo jurídico guarda semelhanças com essa corrente de pensamento - sendo chamado, inclusive, de positivismo fático. ${ }^{44}$ Isso porque, para ambas as tradições, o Direito é visto como mera questão de fato, ${ }^{45}$ preocupando-se, as duas, tão somente com a dimensão descritiva da atividade judicial.

${ }^{37}$ SANTOS, Pedro Felipe de Oliveira. Como os juízes julgam? Reflexões sobre a escola do realismo jurídico. In: FONSECA, Reynaldo Soares da; VELOSO, Roberto Carvalho (org.). Justiça Federal: estudos em homenagem ao desembargador federal Leomar Amorim. Belo Horizonte: D’Plácido, 2016. p. 683-684.

${ }^{38}$ STRECK, Lenio Luiz. Dicionário de Hermenêutica: 50 verbetes fundamentais da Teoria do Direito à luz da Crítica Hermenêutica do Direito. 2. ed. Belo Horizonte: Letramento; Casa do Direito, 2020.

${ }^{39}$ CESTARI, Roberto Tagliari. Decisão judicial e realismo jurídico: evolução das pesquisas sobre o comportamento judicial. Dissertação (Mestrado em Direito) - Universidade de São Paulo, Ribeirão Preto, 2016. Disponível em: https://doi.org/10.11606/D.107.2017.tde-01092017-094644. Acesso em: 15 jan. 2021.

${ }^{40}$ Vieses cognitivos são uma espécie de atalho mental que leva a certa irracionalidade. Por meio do viés, se tem uma distorção de julgamento, causada pela falha na percepção ou na interpretação lógica. COLUCCI NETO, Victor. Reflexões sobre a formação da decisão judicial à luz do realismo jurídico. Teorias do Direito e Realismo Jurídico, Goiânia, v. 5, n. 1, p. 23-44, jan./jun. 2019. Disponível em: https://doi.org/10.26668/ IndexLawJournals/25259601/2019.v5i1.5574. Acesso em: 4 fev. 2021.

${ }^{41}$ Segundo Colucci Neto, heurística é “[...] uma espécie de atalho cognitivo que ajuda a encontrar respostas adequadas, ainda que geralmente imperfeitas, para perguntas difíceis". De acordo com Boeing, esses atalhos mentais funcionam como "mecanismos de decisão pré-pronta". Desse modo, podemos conceituar heurística como uma fórmula pré-pronta que a mente do ser humano desenvolve para uma resposta rápida a um problema que exigiria esforço para sua solução. COLUCCI NETO, Victor. Reflexões sobre a formação da decisão judicial à luz do realismo jurídico. Teorias do Direito e Realismo Jurídico, Goiânia, v. 5, n. 1, p. 33, jan./jun. 2019. Disponível em: https://doi.org/10.26668/IndexLawJournals/2525-9601/2019.v5i1.5574. Acesso em: 4 fev. 2021. BOEING, Daniel Henrique Arruda. Ensinando um robô a julgar: pragmática, discricionariedade e vieses no uso de aprendizado de máquina no Judiciário. Trabalho de Conclusão de Curso (Graduação em Direito) - Universidade Federal de Santa Catarina, $\quad$ Florianópolis, $2019 . \quad$ Disponível em: https://repositorio.ufsc.br/ bitstream/handle/123456789/203514/TCC\%20-\%20Ensinando\%20um\%20rob\%c3\%b4\%20a\%20julgar\%201-3merged.pdf?sequence $=1 \&$ is Allowed $=y$. Acesso em: 15 jan. 2021. p. 60 .

${ }^{42}$ No tocante à economia, vem obtendo cada vez mais destaque a análise econômica do direito, proposta inicialmente por Richard Posner. STRECK, Lenio Luiz. Dicionário de Hermenêutica: 50 verbetes fundamentais da Teoria do Direito à luz da Crítica Hermenêutica do Direito. 2. ed. Belo Horizonte: Letramento; Casa do Direito, 2020.

${ }^{43}$ SANTOS, Pedro Felipe de Oliveira. Como os juízes julgam? Reflexões sobre a escola do realismo jurídico. In: FONSECA, Reynaldo Soares da; VELOSO, Roberto Carvalho (org.). Justiça Federal: estudos em homenagem ao desembargador federal Leomar Amorim. Belo Horizonte: D’Plácido, 2016. p. 681-696.

${ }^{44}$ STRECK, Lenio Luiz. O que é isto: decido conforme minha consciência? Porto Alegre: Livraria do Advogado, 2013.

${ }^{45}$ STRECK, Lenio Luiz. Um robô pode julgar? Quem programa o robô? Consultor Jurídico, São Paulo, 2020. Disponível em: https://www.conjur.com.br/2020-set-03/senso-incomum-robo-julgar-quem-programa-robo. Acesso em: 9 jan. 2021. 
Neste ponto, cabe uma breve síntese da cisão entre análises descritivas e prescritivas - entre “ser" e "dever ser". No estudo de um problema (como a indagação acerca do que é uma decisão judicial, por exemplo), tornou-se usual a divisão entre essas duas abordagens contrapostas: como a situação é (descrição) e como ela deveria ser (prescrição). ${ }^{46}$ Entretanto, essa partição só é possível se baseada em uma relação sujeito-objeto, em que se ignora a “[...] dupla estrutura da linguagem e [o] fato de que, ao descrever, já prescrevemos [...]". 47

Para a Crítica Hermenêutica do Direito, não se pode falar em uma objetividade descritiva do Direito, eis que para isso seria necessário admitir a existência de um "grau zero de sentido". Sob o ponto de vista hermenêutico, sempre se tem uma pré-compreensão e falar em grau zero já é assumir um ponto de vista. ${ }^{48}$ Nesse sentido, o realismo jurídico, ao apresentar-se como uma forma descritiva de compreender o Direito, o instrumentaliza - eis que, para descrever, sempre recorre a outras ciências - além de deixar margem para discricionariedades na atividade do magistrado.

Diante dessas considerações, tem-se elementos para compreender como o uso de sistemas computacionais na atividade jurisdicional pode ser visto sob a perspectiva da Crítica Hermenêutica do Direito. Sob um ponto de vista prático, verifica-se que a inteligência artificial realiza uma tarefa de processamento de dados inseridos em um sistema (inputs), entregando um resultado da análise e articulação desses dados (outputs) no formato para o qual for planejado. Ao analisar pedidos e documentos em um processo, com a finalidade de propor uma decisão judicial, o algoritmo realiza uma série de escolhas - orientadas pelo modelo de sua programação - com base naquilo que aprendeu que é uma decisão. Ou seja, dentre diversas possibilidades, a máquina escolhe a mais adequada para sua finalidade.

Com o uso de algoritmos na tomada de decisão judicial, o protagonismo do juiz é substituído pelo protagonismo do robô. ${ }^{49}$ Para aprender o que é uma decisão, a máquina precisa conhecer outras decisões. São esses dados que servirão de parâmetro para o algoritmo, ou seja, "Vale dizer, para esse

\footnotetext{
${ }^{46}$ CESTARI, Roberto Tagliari. Decisão judicial e realismo jurídico: evolução das pesquisas sobre o comportamento judicial. Dissertação (Mestrado em Direito) - Universidade de São Paulo, Ribeirão Preto, 2016. Disponível em: https://doi.org/10.11606/D.107.2017.tde-01092017-094644. Acesso em: 15 jan. 2021.

${ }^{47}$ STRECK, Lenio Luiz. Dicionário de Hermenêutica: 50 verbetes fundamentais da Teoria do Direito à luz da Crítica Hermenêutica do Direito. 2. ed. Belo Horizonte: Letramento; Casa do Direito, 2020. p. 269.

${ }^{48}$ STRECK, Lenio Luiz. Dicionário de Hermenêutica: 50 verbetes fundamentais da Teoria do Direito à luz da Crítica Hermenêutica do Direito. 2. ed. Belo Horizonte: Letramento; Casa do Direito, 2020. p. 270.

${ }^{49}$ STRECK, Lenio Luiz. Um robô pode julgar? Quem programa o robô? Consultor Jurídico, São Paulo, 2020. Disponível em: https://www.conjur.com.br/2020-set-03/senso-incomum-robo-julgar-quem-programa-robo. Acesso em: 9 jan. 2021.
} 
sistema de Inteligência Artificial, o Direito aplicável ao caso consiste naquilo que a decisão judicial pretérita definiu". ${ }^{50}$ Grande indício de que o uso de computadores para essa finalidade só é possível se baseada em uma teoria pragmatista.

Outro problema é que a tarefa do magistrado não é simplesmente a de escolher a resposta mais adequada dentre tantas - é interpretar, coisa que a máquina é incapaz de fazer. ${ }^{51} \mathrm{~A}$ escolha é discricionária, enquanto a decisão é pautada pela pré-compreensão daquilo que a comunidade política entende como Direito - sabendo-se que não existe grau zero de sentido, mas também que précompreensão é completamente diferente de pré-conceitos subjetivos. Nas palavras de Streck:

\begin{abstract}
A escolha, ou a eleição de algo, é um ato de opção que se desenvolve sempre que estamos diante de duas ou mais possibilidades, sem que isso comprometa algo maior do que o simples ato presentificado em uma dada circunstância. Em outras palavras, a escolha é sempre parcial. Há no direito uma palavra técnica para se referir à escolha: discricionariedade e, quiçá (ou na maioria das vezes), arbitrariedade. [...] Ora, a decisão se dá, não a partir de uma escolha, mas, sim, a partir do comprometimento com algo que se antecipa. No caso da decisão jurídica, esse algo que se antecipa é a compreensão daquilo que a comunidade política constrói como direito (ressalte-se, por relevante, que essa construção não é a soma de diversas partes, mas, sim, um todo que se apresenta como a melhor interpretação - mais adequada - do direito). ${ }^{52}$
\end{abstract}

Critica-se, também, o instrumentalismo gerado pela adoção da tecnologia nesses termos, que impacta na necessária autonomia do Direito. ${ }^{53}$ Diretamente relacionada à democracia e ao Estado Constitucional, essa autonomia significa a resistência do Direito aos seus predadores exógenos e endógenos. ${ }^{54}$ No caso do uso de inteligência artificial para tomada de decisões, a atividade predatória está na discricionariedade que a prática possibilita, assim como na promessa de uma satisfação utilitarista das necessidades sociais - com a valorização de uma prestação jurisdicional mais quantitativa, em detrimento da qualidade e da busca pela resposta adequada enquanto direito fundamental do Estado Democrático de Direito.

\footnotetext{
${ }^{50}$ MEDINA, José Miguel Garcia; MARTINS, João Paulo Nery dos Passos. A era da inteligência artificial: as máquinas poderão tomar decisões judiciais? Revista dos Tribunais, [s. l.], v. 1020/2020, p. 4, out. 2020. Disponível em: https://cutt.ly/0knyKSP. Acesso em: 15 jan. 2020.

${ }^{51}$ STRECK, Lenio Luiz. Um robô pode julgar? Quem programa o robô? Consultor Jurídico, São Paulo, 2020. Disponível em: https://www.conjur.com.br/2020-set-03/senso-incomum-robo-julgar-quem-programa-robo. Acesso em: 9 jan. 2021.

${ }^{52}$ STRECK, Lenio Luiz. O que é isto: decido conforme minha consciência? Porto Alegre: Livraria do Advogado, 2013.

${ }^{53}$ STRECK, Lenio Luiz. Um robô pode julgar? Quem programa o robô? Consultor Jurídico, São Paulo, 2020. Disponível em: https://www.conjur.com.br/2020-set-03/senso-incomum-robo-julgar-quem-programa-robo. Acesso em: 9 jan. 2021.

${ }^{54}$ STRECK, Lenio Luiz. Dicionário de Hermenêutica: 50 verbetes fundamentais da Teoria do Direito à luz da Crítica Hermenêutica do Direito. 2. ed. Belo Horizonte: Letramento; Casa do Direito, 2020.
} 
Além disso, apresenta-se a tecnologia de inteligência artificial como uma alternativa para a tomada de decisões judiciais em casos tidos como fáceis ${ }^{55}$ Essa proposta pressupõe a cisão entre easy cases, casos simples, que pudessem ser decididos simplesmente por meio de deduções/subsunções, e hard cases, casos difíceis, que exigiriam a elaboração "[...] de uma racionalidade discursiva que assegurasse condições para uma universalização do processo de atribuição de sentido". ${ }^{56}$ Tal divisão, entretanto, é rejeitada pela Crítica Hermenêutica do Direito.

Nas palavras de Streck, “[...] um hard case só existe porque ainda não foi compreendido. E um easy case é um hard case que foi compreendido. Ou, de outro modo: a cisão entre easy e hard cases já é um hard case". ${ }^{57}$ Nesse sentido, o autor aponta que:

Acreditar na cisão entre casos (fáceis) simples e casos difíceis (complexos) é pensar que o Direito se insere em uma "suficiência ôntica", enfim, que a "completude" do mundo jurídico pode ser "resolvida" por raciocínios causais-explicativos, em uma espécie de "positivismo da causalidade". Pensar assim é esquecer que essa "metafísica da causalidade" é apenas uma etapa necessária para chegarmos aos entes. Entretanto, não é suficiente, pois, presa à causalidade [...], ela não atinge os entes em seu acontecer (na sua compreensão). ${ }^{58}$

Por esse motivo, cabem também as críticas realizadas ao positivismo. Aceitar que existem casos fáceis, previamente assim classificáveis, é assumir que é possível uma mera subsunção da lei ao caso concreto, ignorando as particularidades e a complexidade de cada situação. ${ }^{59}$ Assim, nas palavras de Engelmann:

\footnotetext{
Para este ângulo de visualização do processo de subsunção, o direito se apresenta como algo já dado. Neste particular, reside a inadequação da proposta do modelo positivista, porque o direito é algo que deve ser buscado incessantemente. [...] O que a proposta do raciocínio jurídico, através do silogismo, não consegue dar conta é a contextualização sistemática do direito, pois os textos legais, os costumes e os princípios, exteriorizados através das crenças,
}

\footnotetext{
${ }^{55}$ ENGELMANN, Wilson; FRÖHLICH, Afonso Vinício Kirschner. Inteligência artificial aplicada à decisão judicial: o papel dos algoritmos no processo de tomada de decisão. Revista Jurídica, Blumenau, v. 24, n. 54, e8274, mai./ago. 2020. Disponível em: https://proxy.furb.br/ojs/index.php/juridica/issue/view/474. Acesso em: 9 jan. 2021.

${ }^{56}$ STRECK, Lenio Luiz. Verdade e consenso. 6 ed. rev. e ampl. São Paulo: Saraiva, 2017. E-book. p. 330.

${ }^{57}$ STRECK, Lenio Luiz. Um robô pode julgar? Quem programa o robô? Consultor Jurídico, São Paulo, 2020. Disponível em: https://www.conjur.com.br/2020-set-03/senso-incomum-robo-julgar-quem-programa-robo. Acesso em: 9 jan. 2021.

${ }^{58}$ STRECK, Lenio Luiz. Verdade e consenso. 6 ed. rev. e ampl. São Paulo: Saraiva, 2017. E-book. p. 334.

${ }^{59}$ ENGELMANN, Wilson; FRÖHLICH, Afonso Vinício Kirschner. Inteligência artificial aplicada à decisão judicial: o papel dos algoritmos no processo de tomada de decisão. Revista Jurídica, Blumenau, v. 24, n. 54, e8274, mai./ago. 2020. Disponível em: https://proxy.furb.br/ojs/index.php/juridica/issue/view/474. Acesso em: 9 jan. 2021
} 
das convicções ou das estimativas gerais do grupo humano, proporcionam apenas pautas ou guias para encontrar em cada caso concreto, o que é o direito. ${ }^{60}$

Ademais, assim como uma decisão não é uma escolha, a classificação de um caso como simples ou complexo também não é. O resultado da interpretação não é uma escolha pela resposta mais adequada, nem a assunção de verdades ontológicas - ou seja, o sentido não está "nas coisas" nem na "consciência de si do sujeito pensante", mas se dá em uma dimensão intersubjetiva, mediada pela linguagem. Por isso não se pode falar em um pré-estabelecimento de uma divisão entre casos fáceis e difíceis, é impossível determinar de antemão que determinados casos serão passíveis de mera dedução ou subsunção. ${ }^{61}$

\section{CONSIDERAÇõES FINAIS}

Com o avançado desenvolvimento tecnológico da Quarta Revolução Industrial, que já permite falar no uso de inteligência artificial para a substituição de algumas atividades humanas, tem-se falado no uso de algoritmos para a tomada de decisões judiciais. Mesmo no Brasil, já existem máquinas que auxiliam na análise e classificação de documentos, outras que até mesmo sugerem decisões aos magistrados, embora (ainda) não se tenha robôs que substituam integralmente o juiz.

Diante da promessa de redução de custos e de um incremento de celeridade processual, cada dia mais se têm estudos analisando as possibilidades de implementação do machine learning no Direito. Entretanto, os entusiastas demonstram modelos computacionais, adentram pormenores de teorias psicológicas de tomada de decisão e apresentam estatísticas do funcionamento das máquinas - pouco abordando o que a teoria do Direito tem a dizer sobre a adoção da tecnologia no Judiciário. É por isso que o presente trabalho possuiu, como questão de pesquisa, a seguinte pergunta: em que medida, sob o ponto de vista da Crítica Hermenêutica do Direito, é possível a utilização de ferramentas da tecnologia da informação, especialmente de inteligência artificial, na tomada de decisões judiciais?

${ }^{60}$ ENGELMANN, Wilson. Crítica ao positivismo jurídico: princípios, regras e o conceito de Direito. Porto Alegre: Sergio Antonio Fabris Editor, 2001. p. 156

${ }^{61}$ STRECK, Lenio Luiz. Verdade e consenso. 6 ed. rev. e ampl. São Paulo: Saraiva, 2017. E-book. 
Viu-se que a teoria que parece sustentar a possibilidade de utilização da inteligência artificial na tomada de decisão judicial é o realismo jurídico. Essa espécie de pragmatismo analisa o Direito como um instrumento voltado à realização das necessidades sociais, entregando ao juiz um papel de protagonismo. Para a Crítica Hermenêutica do Direito, essa corrente é nada mais que uma forma de positivismo (fático), suportando também as críticas a ele destinadas.

Nesse sentido, pode-se concluir que, para a Crítica Hermenêutica do Direito, não há possibilidade de que a existência de um robô-juiz seja compatível com o Estado Democrático de Direito. Nem mesmo a sugestão, pelo algoritmo, de uma decisão judicial parece atingir àquilo que se entende como direito fundamental a uma resposta adequada. Porém, não parece haver oposição ao computador realizando atividades meramente de apoio, como o destaque e a classificação de documentos - contanto que não interfira na atividade do magistrado, mas o auxilie sob um ponto de vista mais organizacional. Afinal, a máquina só pode fazer escolhas - enquanto o juiz precisa saber interpretar.

\section{REFERÊNCIAS}

AMBROGI, Robert. ROSS comes out swinging, vows to fight Thomson Reuters' lawsuit alleging data theft. In: AMBROGI, Robert. LawSites. [S. l.], May 7 2020. Disponível em: https://www.lawsitesblog.com/2020/05/ross-comes-out-swinging-vows-to-fight-thomson-reuterslawsuit-alleging-data-theft.html. Acesso em: 2 fev. 2021.

BOEING, Daniel Henrique Arruda. Ensinando um robô a julgar: pragmática, discricionariedade e vieses no uso de aprendizado de máquina no Judiciário. Trabalho de Conclusão de Curso (Graduação em Direito) - Universidade Federal de Santa Catarina, Florianópolis, 2019. Disponível em: https://repositorio.ufsc.br/bitstream/handle/123456789/203514/TCC\%20\%20Ensinando\%20um\%2 0rob\%c3\%b4\%20a\%20julgar\%201-3 merged.pdf?sequence=1\&isAllowed=y. Acesso em: 15 jan. 2021.

CESTARI, Roberto Tagliari. Decisão judicial e realismo jurídico: evolução das pesquisas sobre o comportamento judicial. Dissertação (Mestrado em Direito) - Universidade de São Paulo, Ribeirão Preto, 2016. Disponível em: https://doi.org/10.11606/D.107.2017.tde-01092017-094644. Acesso em: 15 jan. 2021. 
COLUCCI NETO, Victor. Reflexões sobre a formação da decisão judicial à luz do realismo jurídico. Teorias do Direito e Realismo Jurídico, Goiânia, v. 5, n. 1, p. 23-44, jan./jun. 2019. Disponível em: https://doi.org/10.26668/IndexLawJournals/2525-9601/2019.v5i1.5574. Acesso em: 4 fev. 2021.

CONSELHO NACIONAL DE JUSTIÇA (CNJ). Resolução no 332, de 21 de agosto de 2020. Brasília, DF: CNJ, 2020. Disponível em: https://www.anoreg.org.br/site/wpcontent/uploads/2020/08/Resoluc\%CC\%A7a\%CC\%83o-332-CNJ.pdf. Acesso em: 26 ago. 2020.

ENGELMANN, Wilson; FRÖHLICH, Afonso Vinício Kirschner. Inteligência artificial aplicada à decisão judicial: o papel dos algoritmos no processo de tomada de decisão. Revista Jurídica, Blumenau, v. 24, n. 54, e8274, mai./ago. 2020. Disponível em: https://proxy.furb.br/ojs/index.php/juridica/issue/view/474. Acesso em: 9 jan. 2021.

ENGELMANN, Wilson. Crítica ao positivismo jurídico: princípios, regras e o conceito de Direito. Porto Alegre: Sergio Antonio Fabris Editor, 2001.

FREY, Carl Benedikt; OSBORNE, Michael A. The future of employment: how susceptible are jobs to computerisation? Oxford: University of Oxford, 2013. Disponível em: https://linkinghub.elsevier.com/retrieve/pii/S0040162516302244. Acesso em: 30 jan. 2021.

INTELIGÊNCIA artificial vai agilizar a tramitação de processos no STF. In: SUPREMO TRIBUNAL FEDERAL (STF). Notícias STF. Brasília, DF, 30 maio 2018. Disponível em: http://www.stf.jus.br/portal/cms/verNoticiaDetalhe.asp?idConteudo=380038. Acesso em: 9 jan. 2021.

MEDINA, José Miguel Garcia; MARTINS, João Paulo Nery dos Passos. A era da inteligência artificial: as máquinas poderão tomar decisões judiciais? Revista dos Tribunais, [s. l.], v. 1020/2020, out. 2020. Disponível em: https://cutt.ly/0knyKSP. Acesso em: 15 jan. 2020.

NASCIMENTO, Heloisa Kreutz do. O que são Atos no SAJ Tribunais? In: QUÍRON. [S. l.], 22 jan. 2021. Disponível em: https://quiron.softplan.com.br/hc/pt-br/articles/360016031993-O-ques\%C3\%A3o-Atos-no-SAJ-Tribunais-. Acesso em: 3 fev. 2021.

ROSS INTELLIGENCE. Features. San Francisco: ROSS, [2020?]. Disponível em: https://rossintelligence.com/features.html. Acesso em: 2 fev. 2021.

ROSS, o primeiro robô advogado do mundo. In: TRANSFORMAÇÃO Digital. São Paulo, 6 jun. 2018. Disponível em: https://transformacaodigital.com/juridico/ross-o-primeiro-robo-advogado-domundo. Acesso em: 2 fev. 2021.

RUSSELL, Stuart; NORVIG, Peter. Inteligência artificial. Rio de Janeiro: Elsevier, 2013. E-book (não paginado).

SANTOS, Pedro Felipe de Oliveira. Como os juízes julgam? Reflexões sobre a escola do realismo jurídico. In: FONSECA, Reynaldo Soares da; VELOSO, Roberto Carvalho (org.). Justiça Federal: 
estudos em homenagem ao desembargador federal Leomar Amorim. Belo Horizonte: D’Plácido, 2016. p. 681-696.

SCHWAB, Klaus. A Quarta Revolução Industrial. São Paulo: EDIPRO, 2019. E-book (não paginado).

SOURDIN, Tania. Judge v Robot? Artificial intelligence and judicial decision-making. University of New South Wales Law Journal, Sydney, v. 41, n. 4, p. 1114-1133, 2018. Disponível em: http://www8.austlii.edu.au/cgi-bin/viewdoc/au/journals/UNSWLawJl/2018/38.html. Acesso em: 3 fev. 2021.

SOUSA, Weslei Gomes De. Inteligência artificial e celeridade processual no Judiciário: mito, realidade ou necessidade? Dissertação (Mestrado em Administração) - Universidade de Brasília, Brasília, DF, 2020. Disponível em: https://repositorio.unb.br/bitstream/10482/38772/1/2020_WesleiGomesdeSousa.pdf. Acesso em: 4 fev. 2021.

STRECK, Lenio Luiz. Dicionário de Hermenêutica: 50 verbetes fundamentais da Teoria do Direito à luz da Crítica Hermenêutica do Direito. 2. ed. Belo Horizonte: Letramento; Casa do Direito, 2020.

STRECK, Lenio Luiz. Lições de Crítica Hermenêutica do Direito. Porto Alegre: Livraria do Advogado, 2014.

STRECK, Lenio Luiz. O que é isto: decido conforme minha consciência? Porto Alegre: Livraria do Advogado, 2013.

STRECK, Lenio Luiz. Um robô pode julgar? Quem programa o robô? Consultor Jurídico, São Paulo, 2020. Disponível em: https://www.conjur.com.br/2020-set-03/senso-incomum-robo-julgarquem-programa-robo. Acesso em: 9 jan. 2021.

STRECK, Lenio Luiz. Verdade e consenso. 6 ed. rev. e ampl. São Paulo: Saraiva, 2017. E-book.

SUSSKIND, Richard; SUSSKIND, Daniel. The future of the professions: how technology will transform the work of human experts. Oxford: Oxford University Press, 2015.

SUSSKIND, Richard. Tomorrow's lawyers: an introduction to your future. 2. ed. Oxford: Oxford University Press, 2017.

TACCA, Adriano; ROCHA, Leonel Severo. Inteligência artificial: reflexos no sistema do direito. Revista do Programa de Pós-Graduação em Direito da UFC, Fortaleza, v. 38, n. 2, p. 53-68, jul./dez. 2018. Disponível em: www.periodicos.ufc.br/nomos/article/download/20493/95963. Acesso em: 15 jan. 2021. 
VERITAS. Plataforma eDiscovery: investigação digital, investigações e revisão de documentos. Santa Clara: Veritas, [2021?]. Disponível em: https://www.veritas.com/pt/br/insights/ediscoveryplatform. Acesso em: 2 fev. 2021. 